\title{
Atributos qualitativos e maturação de genótipos de sorgo sacarino
}

\author{
Jean Cecchin Biondo ${ }^{1} \odot$, Sandro Luis Petter Medeiros ${ }^{1} \mathbb{0}$, Silvia Cristina Paslauski Nunes ${ }^{1}{ }^{\circ}$, \\ Pablo Reno Sangoi ${ }^{1} \oplus$, Andriéli Hedlund Bandeira² ${ }^{\circledR}$, Nayra Grazielle da Silva ${ }^{1}(\mathbb{0}$

\footnotetext{
1 Universidade Federal de Santa Maria, Santa Maria, RS, Brasil. E-mail: jeanbiondo@hotmail.com; slpmedeiros@yahoo.com.br; spaslauski@yahoo.com.br; prsangoi@hotmail.com; nayra.grazielle@gmail.com

${ }^{2}$ Instituto Federal Farroupilha, Campus Alegrete, Alegrete, RS, Brasil. E-mail: andrieli_hedlund@hotmail.com
}

RESUMO: O objetivo com este trabalho foi avaliar os atributos qualitativos do caldo e a maturação de onze genótipos de sorgo sacarino, em dois anos de cultivo. O experimento de campo foi conduzido em Santa Maria, Estado do Rio Grande do Sul, Região Sul, Brasil, nos anos agrícolas de 2012/13 e 2013/14. Foi utilizado o delineamento experimental de blocos ao acaso com três repetições e os tratamentos foram compostos por onze materiais genéticos, sendo sete variedades (BRS506, BRS511, Fepagro 17, Fepagro 19, Past 81-04, Past 29-51 e Past 29-49) e quatro híbridos (CV007, CV147, CV568 e CV198). Foram avaliados os atributos qualitativos sacarose do caldo (\%), açúcares redutores do caldo (\%), pureza do caldo (\%), sólidos solúveis totais ( ${ }^{\circ}$ Brix), açúcar total recuperável $\left(\mathrm{kg} \mathrm{t}^{-1}\right)$, fibra $(\%)$, rendimento de etanol $\left(\mathrm{I} \mathrm{ha}^{-1}\right)$ e também as curvas de maturação para a obtenção do período de utilização industrial (PUI). Os genótipos BRS506, BRS511 e CV198 apresentaram PUI superior a 30 dias. Os genótipos BRS506 e BRS511 apresentaram melhores características para produção de etanol.

Palavras-chave: brix; caldo; etanol; Sorghum bicolor

\section{Qualitative parameters and maturity in sweet sorghum genotypes}

ABSTRACT: The aim with this work was to evaluate the qualitative parameters and maturation of eleven genotypes of sweet sorghum. Field experiment was carried out in Santa Maria locality, State of the Rio Grande do Sul, South Region, Brazil, in two growing seasons (2012/13 and 2013/14). The experimental design was randomized blocks with three replications and the treatments consisted of eleven genotypes, seven varieties (BRS506, BRS511, Fepagro 17, Fepagro 19, Past 81-04, Past 29-51 and Past 29-49) and four hybrids (CV007, CV147, CV568 and CV198). The qualitative parameters were evaluated: sucrose content $(\%)$, reducing sugars (\%), purity (\%), total soluble solids ( ${ }^{\circ}$ Brix), total recoverable sugar $\left(\mathrm{kg} \mathrm{t}^{-1}\right)$, fiber $(\%)$ and ethanol production $\left(\mathrm{I} \mathrm{ha}^{-1}\right)$. It was determined maturity curves to characterize the industrial use period (IUP). The genotypes BRS506, BRS511 and CV198 showed IUP over 30 days. BRS506 and BRS511 are genotypes with better features for ethanol production.

Key words: brix; juice; ethanol; Sorghum bicolor 


\section{Introdução}

A crescente demanda mundial por fontes de energia renováveis tem motivado a pesquisa a retomar os estudos com culturas agroenergéticas, como o sorgo sacarino. No cenário mundial, o IPCC (2011) afirma que a elevação da temperatura do ar na superfície terrestre está relacionada à queima de combustíveis fósseis, principalmente aqueles produzidos a partir do petróleo. A queima destes combustíveis contribui para o aumento da concentração dos gases do efeito estufa na atmosfera, como é o caso do dióxido de carbono $\left(\mathrm{CO}_{2}\right)$.

O etanol é um combustível menos poluente que aqueles produzidos a partir do petróleo, além de ser oriundo de matérias-primas renováveis, como a cana-de-açúcar e o sorgo sacarino. Conforme dados da Conab (2015), o Rio Grande do Sul produz cerca de 4,4 milhões de litros de etanol hidratado, uma parcela ínfima quando comparada à produção nacional, que se situa ao redor de 17 bilhões de litros. Além disso, os custos com o transporte do etanol dos estados produtores até o Rio Grande do Sul tornam o produto mais caro nas bombas dos postos de combustíveis.

A cultura do sorgo sacarino (Sorghum bicolor (L.) Moench) apresenta ciclo curto (quatro meses) e produz açúcares no colmo de forma semelhante ao que ocorre com a cana-deaçúcar (Saccharum spp.) (Durães et al., 2012). O sorgo sacarino adapta-se perfeitamente ao setor sucroalcooleiro, pois é capaz de fornecer matéria-prima de qualidade no período de entressafra da cana-de-açúcar, nos meses de verão, reduzindo a instabilidade do mercado brasileiro de etanol e aproveitando o período de ociosidade das usinas (May \& Durães, 2012). Também existe a possibilidade do uso do bagaço como bioproduto do sorgo sacarino, seja através de sua queima para geração de energia, produção de papel, silagem para alimentação animal ou fornecimento de fibra para produção de etanol de segunda geração (Almodares \& Hadi, 2009).

No cenário nacional, a Embrapa Milho e Sorgo iniciou seu programa de desenvolvimento de cultivares de sorgo sacarino após a implantação do Programa Nacional do Álcool, o Proálcool, sendo que as primeiras variedades brasileiras com potencial para produção de etanol foram desenvolvidas em 1987, sendo BRS 506, BRS 507 e o híbrido BRS 601. Após longo período de estagnação, a partir de 2008 a Embrapa retomou as pesquisas com a cultura do sorgo sacarino, devido ao grande potencial na geração de energia renovável e à demanda crescente do setor alcooleiro por matéria-prima alternativa para a produção de etanol (Parrela, 2011).

Quanto à qualidade do sorgo sacarino, Almodares \& Hadi (2009) listaram cultivares com ${ }^{\circ}$ Brix de até $22 \%$ e sacarose na faixa de 6 a $16 \%$ e híbridos com ${ }^{\circ}$ Brix máximo de $21 \%$ e sacarose variando de 9 a 14\%. De acordo com Smith \& Buxton (1993) a determinação do teor de sacarose e açúcares redutores presentes no caldo do sorgo sacarino é necessária para se estimar o rendimento de etanol da cultura. No estudo de Zhao et al. (2009) foi determinado o rendimento de etanol produzido a partir do açúcar do caldo, apresentando variação de 709 a $5.414 \mathrm{I} \mathrm{ha}^{-1}$, em dois anos de cultivo.
No Brasil, dentre outros, existem os trabalhos de Câmara et al. (2018) e Lessa et al. (2018) que abordaram a qualidade industrial e produção de etanol de genótipos de sorgo sacarino. Mais especificamente no Rio Grande do Sul, ainda são escassas as pesquisas relacionadas à cultura do sorgo sacarino, citando-se o trabalho de Emygdio (2011) que avaliou a cultivar BRS 506 sob diferentes manejos em ambientes contrastantes.

Em virtude do potencial da cultura do sorgo sacarino de participar da matriz energética para produção de etanol, o objetivo deste trabalho foi avaliar os atributos qualitativos e as curvas de maturação de sete variedades e quatro híbridos de sorgo sacarino em dois anos de cultivo em Santa Maria-RS.

\section{Material e Métodos}

Os experimentos foram conduzidos na área experimental do Departamento de Fitotecnia da Universidade Federal de Santa Maria, em Santa Maria, Rio Grande do Sul, Brasil $\left(29^{\circ} 43^{\prime} 28^{\prime \prime} \mathrm{S}, 53^{\circ} 43^{\prime} 18^{\prime \prime} \mathrm{W}\right.$, altitude $\left.95 \mathrm{~m}\right)$, nos anos agrícolas de 2012/13 e 2013/14. O clima da região é do tipo Cfa, subtropical úmido com verões quentes e sem estação seca definida, de acordo com a classificação de Köeppen (Moreno, 1961). O solo é um Argissolo Vermelho Distrófico arênico, pertencente à Unidade de Mapeamento São Pedro (Embrapa, 1999). Os dados de temperatura do ar e precipitação foram obtidos no Banco de Dados Meteorológicos para Ensino e Pesquisa (BDMEP) do Instituto Nacional de Meteorologia (INMET, 2015). Este trabalho faz parte da Rede de Avaliação de Cultivares de Sorgo Sacarino no Rio Grande do Sul, organizada pela Embrapa.

O preparo da área foi realizado através de gradagens para homogeneizar o solo e incorporar o calcário. Foi realizada aplicação de calcário PRNT $87 \%$ visando elevar o pH do solo até 6,0 . A amostragem do solo foi efetuada na profundidade de 0-0,2 $\mathrm{m}$ e o resultado da análise indicou a aplicação de 120 $\mathrm{kg} \mathrm{ha}^{-1}$ de N (20 kg ha-1 na semeadura e o restante dividido em quantidades iguais em duas aplicações em cobertura), 110 $\mathrm{kg} \mathrm{ha}^{-1}$ de $\mathrm{P}_{2} \mathrm{O}_{5}$ na semeadura e $80 \mathrm{~kg} \mathrm{ha}^{-1}$ de $\mathrm{K}_{2} \mathrm{O}\left(60 \mathrm{~kg} \mathrm{ha}^{-1}\right.$ na semeadura e o restante em uma aplicação em cobertura), de acordo com as recomendações da Comissão de Química e Fertilidade do Solo RS/SC (2004). A semeadura foi realizada manualmente, em linhas, na profundidade de 0,02-0,03 m, em 27 de novembro em ambos os anos de cultivo e na mesma área. Após a emergência das plantas foi realizado desbaste visando obter uma população de aproximadamente 140.000 plantas ha-1. Para o controle de plantas daninhas, utilizou-se herbicida à base de Atrazina e capinas manuais. A principal praga incidente foi a lagarta do cartucho do milho (Spodoptera frugiperda) e o seu controle foi realizado utilizando-se inseticidas recomendados para a cultura do sorgo.

O delineamento experimental utilizado foi o de blocos ao acaso com três repetições. Os tratamentos foram compostos por 11 genótipos de sorgo sacarino, sendo sete variedades, duas da Embrapa (BRS506 e BRS511), cinco da Fepagro (Fepagro 17, Fepagro 19, Past 81-04, Past 29-51 e Past 29-49) e 
quatro híbridos da CanaVialis (CV007, CV147, CV568 e CV198), em dois anos agrícolas (2012/13 e 2013/14). As parcelas foram constituídas por três linhas de cinco metros de comprimento, com espaçamento de 0,7 metros nas entrelinhas, perfazendo uma área de $10,5 \mathrm{~m}^{2}$. A bordadura externa do experimento foi constituída de duas linhas no sentido paralelo às linhas das parcelas e 0,5 m no sentido transversal. As coletas de plantas para as avaliações qualitativas, por ocasião da colheita, foram realizadas nos quatro metros da linha central da parcela. As coletas para avaliação das curvas de maturação foram realizadas nas linhas restantes.

Foram avaliados os atributos sacarose do caldo (teor de sacarose aparente ou Pol do caldo, em \%), açúcares redutores do caldo (teor de glicose, frutose e demais substâncias redutoras, em \%), pureza aparente (\% de sacarose em relação ao ${ }^{\circ}$ Brix), teor de sólidos solúveis totais do caldo (\%SST, em ${ }^{\circ}$ Brix), açúcar total recuperável (ATR, expresso em $\mathrm{kg} \mathrm{t}^{-1}$ ), fibra (\%) e rendimento de etanol (I ha $\left.{ }^{-1}\right)$ de acordo com a metodologia do Consecana (2006). O rendimento de etanol foi obtido considerando que $1 \mathrm{~kg}$ de ATR produz 0,59126 litro de etanol, sendo este valor multiplicado pelo valor do ATR $\left(\mathrm{kg} \mathrm{t}^{-1}\right)$. Desta forma obtêm-se o valor de etanol em I $\mathrm{t}^{-1}$, convertido posteriormente para I ha-1 de acordo com a produtividade total de colmos ( $t \mathrm{ha}^{-1}$ ). Por ocasião da colheita foram coletados aleatoriamente cinco colmos, dos quais foi extraído caldo com o auxílio de um engenho elétrico. O caldo coletado foi coado e congelado em recipientes de $300 \mathrm{ml}$ para realização das análises. A colheita foi realizada quando cada genótipo atingiu a maturidade fisiológica, correspondendo ao estádio nove da escala de Vanderlip \& Reeves (1972), período no qual ocorre o maior acúmulo de açúcares no colmo (Chavan et al., 2009). A leitura do ${ }^{\circ}$ Brix foi realizada com um refratômetro portátil. A fibra foi determinada pelo método de Tanimoto (Consecana, 2006). A leitura sacarimétrica foi realizada através do sacarímetro modelo ADS420 e o preparo das amostras seguiu a metodologia descrita por Consecana (2006).

Foram determinadas as curvas de maturação de cada genótipo através do ${ }^{\circ}$ Brix do caldo, sendo que as coletas de caldo iniciaram no estádio seis da escala de Vanderlip \& Reeves (1972), correspondendo à metade do florescimento e se estenderam até a senescência da cultura. Foi coletada uma planta por parcela ao longo do período de avaliação. A análise do ${ }^{\circ}$ Brix do caldo para as curvas de maturação foi efetuada conforme descrito anteriormente. As curvas de maturação definem o período de utilização industrial (PUI), considerado por May et al. (2012) como sendo o período no qual o ${ }^{\circ}$ Brix mantêm-se acima de $14,5 \%$, correspondendo a uma concentração de açúcares redutores totais acima de $12,5 \%$ e extração de açúcar superior a $80 \mathrm{~kg} \mathrm{t}^{-1}$, estando assim apto para a colheita.

$O$ acamamento foi quantificado pela contagem das plantas inclinadas a uma altura inferior a $0,5 \mathrm{~m}$ do solo, bem como plantas com o colmo quebrado, sendo que os resultados foram expressos em porcentagem. Os dados de velocidade do vento (rajada) foram obtidos na Estação Meteorológica Automática de Santa Maria ( $\left.8^{\circ} \mathrm{DISME} / \mathrm{RS}\right)$.
Os dados foram submetidos aos testes de normalidade dos erros (Teste de Anderson-Darling) e homogeneidade de variâncias (Teste de Bartlett) utilizando o suplemento Action. Posteriormente, os dados foram submetidos à análise de variância conjunta e as médias comparadas pelo teste de Scott Knott a $5 \%$ de probabilidade de erro. Foi utilizado o programa estatístico Sisvar para a realização destas análises (Ferreira, 2008).

\section{Resultados e Discussão}

A interação entre genótipos e anos de cultivo foi significativa $(p<0,05)$ para todas as variáveis analisadas, exceto para a fibra, demonstrando a ação do ambiente de cultivo (ano) sobre os genótipos. Martins (2013) observou interação significativa entre safras (anos de cultivo), cultivares e épocas de colheita para as variáveis SST, ART, Pol, pureza, ATR e produtividade de etanol, em Sete Lagoas-MG. A ação do ambiente de cultivo (ano) foi decorrente da variabilidade das condições meteorológicas ocorridas, sendo que a temperatura média do ar foi superior no ano agrícola de 2013/14, quando comparada com a normal e com o ano 2012/13 (Figura 1). Além disso, foram observados danos ocasionados por ventos fortes ocorridos durante a fase vegetativa da cultura no ano de 2012/13 e, na fase reprodutiva no ano de 2013/14 (Figura 2), fator que contribuiu para a interação entre ambiente de cultivo e genótipos. Os danos mais intensos ocasionados pelo vento foram observados no segundo ano de cultivo e estão relacionados ao maior porte das plantas (Figura 2), com panículas em fase de enchimento de grãos, associados ainda à ocorrência de chuvas acima do normal para o mês de março de 2014 , o que incrementou o peso da parte aérea

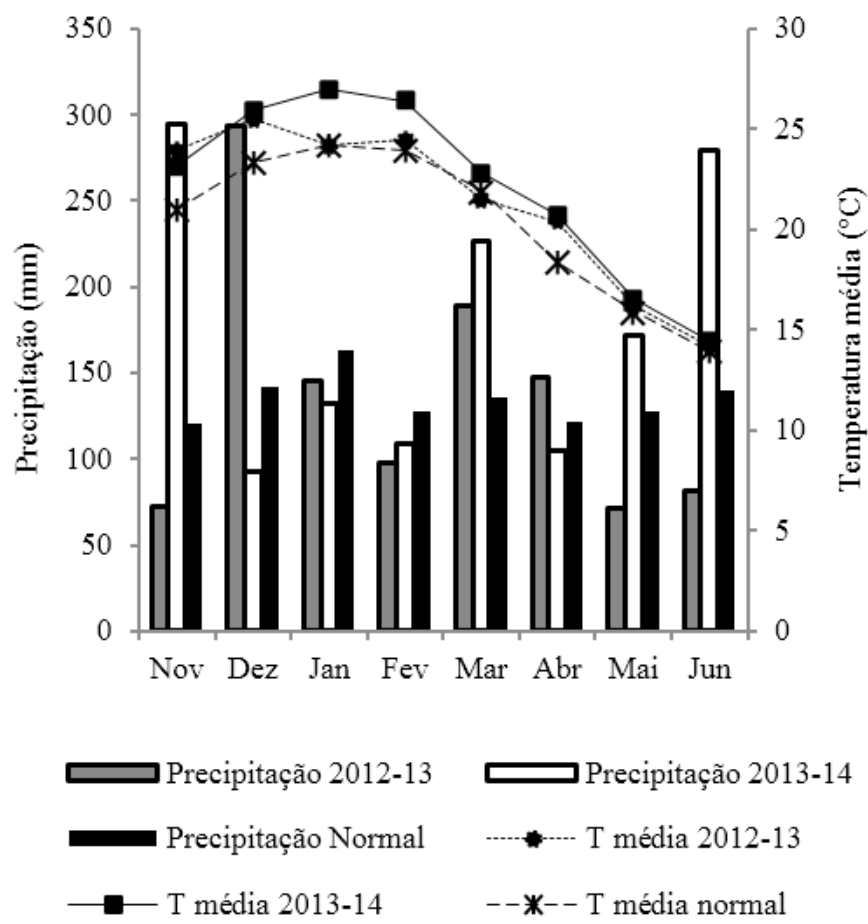

Figura 1. Médias mensais de temperatura do ar e precipitação pluvial, em 2012-13 e 2013-14. 


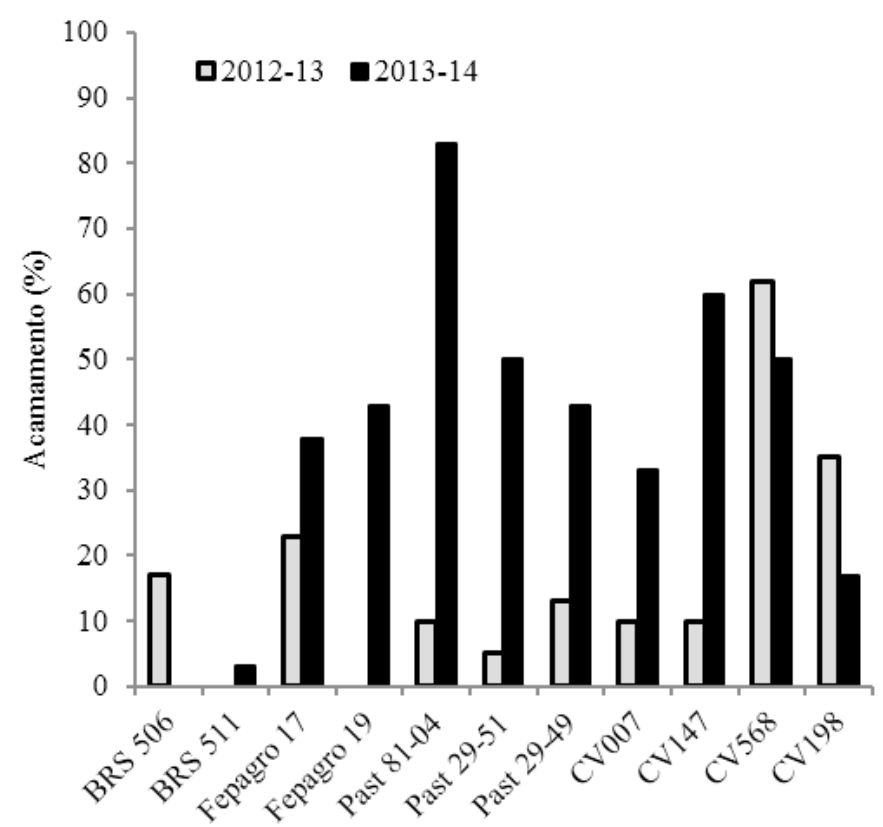

Figura 2. Acamamento de plantas de sorgo sacarino, nos anos de 2012-13 e 2013-14.

(Figura 1), além de diminuir a ancoragem das plantas pelo umedecimento excessivo do solo, facilitando o acamamento. De forma semelhante ao observado neste estudo, Alvim et al. (2010) verificaram associação do aumento do peso da parte aérea e o umedecimento demasiado do solo ocasionados pelo excesso de chuvas com o aumento do acamamento da cultura do milho.

Para o teor de açúcares redutores do caldo (AR caldo) foi observado que os genótipos Fepagro 17, Fepagro 19, Past 81-04 e Past 29-51 apresentaram as maiores médias considerando os dois anos de cultivo (Tabela 1). Os menores valores de AR caldo corresponderam aos genótipos BRS506, BRS511 e CV198, em ambos os anos. Chavan et al. (2009) encontraram valores semelhantes aos observados no presente trabalho, com variação de 0,69 a 2,75\% de açúcares redutores no caldo de sorgo sacarino colhido no estádio de maturidade fisiológica. Pacheco (2012) ressalta que altas percentagens de AR caldo podem aumentar a contaminação bacteriológica do caldo, porém, teores abaixo de $3 \%$ não prejudicam o processamento. Destaca-se que os valores de AR caldo do presente trabalho foram inferiores ao valor crítico de $3 \%$.

Para a variável sacarose do caldo (Pol do caldo, \%), as variedades BRS506 e BRS511 destacaram-se nos dois anos de cultivo, sendo que em 2012/13 foram semelhantes à Past 29-49 e em 2013/14 aos híbridos CV007, CV147, CV568 e CV198 (Tabela 1). Destaca-se no segundo ano de cultivo o aumento da sacarose do caldo nos híbridos CV007, CV568 e CV198 em relação ao primeiro ano. Essa resposta pode estar relacionada à ocorrência de maiores valores de temperatura do ar no período de janeiro a março de 2014 (Figura 1), mais adequados aos híbridos, favorecendo a fotossíntese com aumento do teor de sacarose. De acordo com Taiz \& Zeiger (2013), as taxas fotossintéticas são gradativamente aumentadas quando os valores de temperatura se aproximam da ótima para determinada espécie, o que resulta em maior acúmulo de carbono pela planta nessas condições. Abd ElRasek \& Besheit (2009) encontraram valor máximo de sacarose de $11,3 \%$ em dois anos de cultivo avaliando 14 variedades de sorgo sacarino, valor inferior aos obtidos no presente trabalho com os genótipos BRS506, BRS511 e CV198, os quais foram superiores a $12 \%$. Kawahigashi et al. (2013) avaliaram o caldo de 109 variedades e linhagens de sorgo sacarino e encontraram valores de sacarose variando desde 0,37 até $15,87 \%$, enquanto no presente trabalho a variação foi de 4,54 a $12,83 \%$. Essas informações de variabilidade da sacarose observada entre genótipos demonstram a importância de se conhecer os materiais mais adaptados e produtivos para o cultivo em determinada região.

Para o açúcar total recuperável (ATR) foi verificado melhor desempenho dos genótipos BRS506, BRS511 e Past 29-49 no ano de cultivo 2012/13 (Tabela 1). No segundo ano (2013/14), os genótipos de maior destaque foram BRS511, CV007 e CV198. May et al. (2012) avaliaram quatro variedades de sorgo sacarino em Sete Lagoas-MG, sendo que BRS506 apresentou $72,13 \mathrm{~kg} \mathrm{t}^{-1}$, enquanto BRS511 produziu 106,45 $\mathrm{kg} \mathrm{t}^{-1}$ de ATR. Ambas as variedades estiveram entre as mais promissoras

Tabela 1. Atributos qualitativos e rendimento de etanol de sorgo sacarino em Santa Maria, RS, nos anos agrícolas de 2012-13 e 2013-14.

\begin{tabular}{|c|c|c|c|c|c|c|c|c|c|c|c|c|c|}
\hline \multirow[t]{2}{*}{ Genótipo } & \multicolumn{2}{|c|}{$\begin{array}{c}\text { AR caldo } \\
(\%)\end{array}$} & \multicolumn{2}{|c|}{$\begin{array}{c}\text { Sacarose caldo } \\
\text { (Pol \%) }\end{array}$} & \multicolumn{2}{|c|}{$\begin{array}{c}\text { ATR } \\
\left(\mathrm{kg} \mathrm{t}^{-1}\right)\end{array}$} & \multicolumn{2}{|c|}{$\begin{array}{c}{ }^{\circ} \text { Brix } \\
\text { (\% SST) }\end{array}$} & \multicolumn{2}{|c|}{$\begin{array}{c}\text { Rendimento de etanol } \\
\left(\mid \text { ha }^{-1}\right)\end{array}$} & \multicolumn{2}{|c|}{$\begin{array}{c}\text { Pureza } \\
(\%)\end{array}$} & \multirow{2}{*}{$\begin{array}{c}\begin{array}{c}\text { Fibra } \\
(\%)\end{array} \\
-\end{array}$} \\
\hline & $2012 / 13$ & $2013 / 14$ & $2012 / 13$ & $2013 / 14$ & $2012 / 13$ & $2013 / 14$ & $2012 / 13$ & $2013 / 14$ & $2012 / 13$ & $2013 / 14$ & $2012 / 13$ & $2013 / 14$ & \\
\hline \multicolumn{14}{|l|}{ Variedades } \\
\hline BRS506 & $1,14 \mathrm{bA} *$ & $1,41 \mathrm{bA}$ & $12,83 \mathrm{aA}$ & $9,47 a B$ & $113,86 a A$ & $93,34 \mathrm{bA}$ & $17,6 \mathrm{aA}$ & $14,5 \mathrm{bB}$ & $3518,59 a A$ & $3680,64 a A$ & $72,79 a A$ & $65,04 a A$ & $9,63 b$ \\
\hline BRS511 & $1,30 \mathrm{bA}$ & $1,02 b A$ & $10,54 a A$ & $12,74 \mathrm{aA}$ & $95,92 \mathrm{aB}$ & $118,58 \mathrm{aA}$ & $15,4 \mathrm{aA}$ & $16,7 a A$ & $2594,17 \mathrm{bB}$ & $4181,99 \mathrm{aA}$ & $68,13 \mathrm{aA}$ & $76,29 \mathrm{aA}$ & $9,57 b$ \\
\hline Fepagro 17 & $1,91 \mathrm{aA}$ & $1,93 \mathrm{aA}$ & $6,40 \mathrm{bA}$ & $6,72 \mathrm{bA}$ & $63,46 \mathrm{bA}$ & $70,07 \mathrm{cA}$ & $12,6 \mathrm{bA}$ & $12,9 \mathrm{cA}$ & $2017,32 \mathrm{bA}$ & $2734,85 \mathrm{bA}$ & $50,50 \mathrm{bA}$ & $49,91 \mathrm{bA}$ & $12,63 a$ \\
\hline Fepagro 19 & $1,77 a A$ & $1,96 \mathrm{aA}$ & $7,04 \mathrm{bA}$ & $6,30 \mathrm{bA}$ & $68,06 \mathrm{bA}$ & $66,07 \mathrm{cA}$ & $12,8 \mathrm{bA}$ & $12,6 \mathrm{cA}$ & $2156,27 \mathrm{bA}$ & $2390,80 \mathrm{bA}$ & $54,54 \mathrm{bA}$ & $48,86 \mathrm{bA}$ & $12,87 \mathrm{a}$ \\
\hline Past 81-04 & $1,73 \mathrm{aB}$ & $2,19 a A$ & $8,58 \mathrm{bA}$ & $5,30 \mathrm{bB}$ & $82,26 \mathrm{bA}$ & $59,36 \mathrm{cB}$ & $15,3 a A$ & $12,3 \mathrm{cB}$ & $2385,05 \mathrm{bA}$ & $2028,42 b A$ & $55,83 \mathrm{bA}$ & $42,26 \mathrm{bB}$ & $12,10 \mathrm{a}$ \\
\hline Past 29-51 & $2,10 \mathrm{aA}$ & $2,17 a A$ & $5,58 \mathrm{bA}$ & $4,54 \mathrm{bA}$ & $59,95 \mathrm{bA}$ & $53,58 \mathrm{cA}$ & $12,2 \mathrm{bA}$ & $10,3 \mathrm{cA}$ & $1866,87 \mathrm{bA}$ & $2149,34 \mathrm{bA}$ & $44,90 \mathrm{bA}$ & $42,89 \mathrm{bA}$ & $12,42 \mathrm{a}$ \\
\hline Past $29-49$ & $1,55 \mathrm{bA}$ & $1,81 \mathrm{aA}$ & $10,27 \mathrm{aA}$ & $7,42 \mathrm{bA}$ & $96,63 \mathrm{aA}$ & $73,23 \mathrm{cB}$ & $16,8 \mathrm{aA}$ & $13,7 \mathrm{cB}$ & $2995,42 \mathrm{aA}$ & $2761,63 \mathrm{bA}$ & $61,01 \mathrm{aA}$ & $53,49 \mathrm{bA}$ & $11,57 a$ \\
\hline \multicolumn{14}{|l|}{ Híbridos } \\
\hline CV007 & $2,02 a A$ & $1,46 \mathrm{bB}$ & $6,43 \mathrm{bB}$ & $11,06 a A$ & $67,62 \mathrm{bB}$ & $106,68 \mathrm{aA}$ & $13,2 \mathrm{bA}$ & $17,4 \mathrm{aB}$ & $2049,26 \mathrm{bB}$ & $4049,69 a A$ & $47,38 \mathrm{bB}$ & $63,62 \mathrm{aA}$ & $10,20 \mathrm{~b}$ \\
\hline CV147 & $1,78 \mathrm{aA}$ & $1,62 \mathrm{bA}$ & $7,53 \mathrm{bA}$ & $8,97 a A$ & $75,57 \mathrm{bA}$ & $88,80 \mathrm{bA}$ & $13,9 \mathrm{bA}$ & $14,7 \mathrm{bA}$ & $2242,72 b B$ & $3312,29 a A$ & $54,34 \mathrm{bA}$ & $59,06 \mathrm{aA}$ & $10,14 b$ \\
\hline CV568 & $2,01 \mathrm{aA}$ & $1,36 \mathrm{bB}$ & $6,28 \mathrm{bB}$ & $9,96 \mathrm{aA}$ & $62,57 \mathrm{bB}$ & $89,57 \mathrm{bA}$ & $13,1 \mathrm{bA}$ & $14,9 \mathrm{bA}$ & $1827,19 \mathrm{bB}$ & $3412,27 a A$ & $47,61 \mathrm{bB}$ & $66,61 \mathrm{aA}$ & $14,68 \mathrm{a}$ \\
\hline CV198 & $1,57 \mathrm{bA}$ & $1,16 \mathrm{bA}$ & $8,84 \mathrm{bB}$ & $12,43 a A$ & $81,85 \mathrm{bB}$ & $108,86 \mathrm{aA}$ & $14,6 \mathrm{aA}$ & $17,1 \mathrm{aA}$ & $2381,92 b B$ & $3586,08 \mathrm{aA}$ & $60,49 a A$ & $72,48 \mathrm{aA}$ & $12,61 \mathrm{~A}$ \\
\hline Média Geral & 1,72 & 1,64 & 8,21 & 8,63 & 78,88 & 84,38 & 14,3 & 14,3 & 2366,80 & 3117,09 & 56,14 & 58,23 & 11,67 \\
\hline CV (\%) & \multicolumn{2}{|c|}{15,60} & \multicolumn{2}{|c|}{21,68} & \multicolumn{2}{|c|}{16,08} & \multicolumn{2}{|c|}{11,60} & \multicolumn{2}{|c|}{21,71} & \multicolumn{2}{|c|}{13,37} & 14,80 \\
\hline
\end{tabular}

* Médias seguidas pela mesma letra minúscula na coluna e maiúscula na linha não diferem pelo teste Scott Knott a $5 \%$ de probabilidade de erro. Os valores de Fibra correspondem à média dos dois anos de cultivo. AR caldo, açúcares redutores do caldo; ATR, açúcar total recuperável; ${ }^{\circ}$ Brix, \% de sólidos solúveis totais. 
no parâmetro ATR no presente estudo, com médias nos dois anos de 103,6 $\mathrm{kg} \mathrm{t}^{-1}$ para BRS506 e 107,25 kg t-1 para BRS511. Câmara et al. (2018) observaram valores de ATR semelhantes aos obtidos no presente estudo, de 100,5 e 109,2 $\mathrm{kg} \mathrm{t}^{-1}$ para os genótipos BRS506 e BRS511, respectivamente.

O teor de Sólidos Solúveis Totais (SST \%) é um parâmetro de fácil determinação, comumente utilizado para se conhecer o conteúdo aproximado de açúcares no caldo do sorgo sacarino, sendo generalizada a denominação de ${ }^{\circ}$ Brix. De acordo com Kawahigashi et al. (2013), o ${ }^{\circ}$ Brix está correlacionado com o conteúdo total de açúcares, e desta forma, pode ser utilizado como parâmetro na seleção e desenvolvimento de novos materiais ricos em açúcar.

Os genótipos BRS506, BRS511, Past 81-04, Past 29-49 e CV198 apresentaram desempenho superior aos demais para a variável ${ }^{\circ}$ Brix no ano de 2012/13 (Tabela 1 ). Destes, apenas BRS511 e CV198 mantiveram superioridade no segundo ano de cultivo, juntamente com CV007. Os genótipos destacados acima com elevado ${ }^{\circ}$ Brix, exceto Past 81-04 e CV198, também demonstraram as maiores médias para o atributo ATR. Tal resultado apenas confirma a relação existente entre $0^{\circ} \mathrm{Brix} \mathrm{e}$ o teor de açúcares no colmo do sorgo sacarino, corroborando com o estudo de Guigou et al. (2011), os quais encontraram relação linear positiva entre o teor de açúcar total no caldo e o ${ }^{\circ}$ Brix. Pereira Filho et al. (2013), encontraram valores máximos de ${ }^{\circ}$ Brix de 15,93\% e 16,04\%, para as variedades BRS505 e BRS501, respectivamente, enquanto que o híbrido forrageiro BR601 apresentou o menor valor (14,88\%). Estes resultados são inferiores aos encontrados neste trabalho, onde a variedade BRS506 e o híbrido CV007 apresentaram valores de ${ }^{\circ}$ Brix de $17,6 \%$ e 17,4\%, respectivamente.

Os genótipos que apresentaram menores valores de sacarose do caldo, ATR e ${ }^{\circ}$ Brix no segundo ano de cultivo (Tabela 1) foram aqueles que tiveram danos severos em decorrência do acamamento (Figura 2). Fato que corrobora com as constatações de Pereira Filho et al. (2013), os quais relatam que o acamamento pode dificultar a operação de colheita, além de acarretar aumento das perdas de biomassa e de rendimento de caldo e açúcares no sorgo sacarino.

As variedades BRS506 e Past 29-49 apresentaram as maiores médias de rendimento de etanol no ano de 2012/13 (Tabela 1). No ano seguinte (2013/14), destacaramse as variedades BRS506 e BRS511 e todos os híbridos, com médias superiores a $3.300 \mathrm{I} \mathrm{ha}^{-1}$ de etanol. Zhao et al. (2009) encontraram rendimento de etanol de 4.045 a 5.400 I ha-1 para o sorgo sacarino, valores maiores aos encontrados nesse estudo, com a maioria do rendimento situado abaixo de 4.000 I ha-1. Em contrapartida, Davila-Gomez et al. (2011) encontraram rendimentos de etanol que variaram de 620 a $1.051 \mathrm{I} \mathrm{ha}^{-1}$, em experimento realizado no México com cinco cultivares de sorgo sacarino, valores abaixo do menor observado neste estudo de $1.827 \mathrm{I} \mathrm{ha}^{-1}$, obtido com o genótipo CV568. Câmara et al. (2018) observaram variação de 45,6 a 75,7 litros de etanol por tonelada de sorgo sacarino em experimento conduzido em Alagoas. A grande variação observada no rendimento de etanol em diferentes regiões e dentro de uma mesma região demonstra a amplitude genética dos materiais utilizados e mesmo a interação com o ambiente, ressaltando a importância de testes locais para avaliação de desempenho dos genótipos.

Ao analisar a interação entre ambiente de cultivo e atributos qualitativos (Tabela 1), constata-se que os híbridos apresentaram maior interferência do ambiente, principalmente no rendimento de etanol, ocorrendo aumento do mesmo no ano 2013/14. De forma semelhante, Zhao et al. (2009) também verificaram interação significativa entre genótipos e anos de cultivo (ambientes) para o rendimento de etanol. A maior interação verificada com o ambiente no caso dos híbridos pode estar associada a menor variabilidade genética destes materiais quando comparados às variedades, as quais mantiveram rendimento similar nos dois anos de cultivo, excetuando-se BRS511, que apresentou aumento do primeiro para o segundo ano. Acrescenta-se ainda que os maiores valores de temperatura do ar ocorridos no segundo ano de cultivo (Figura 1) proporcionaram condições mais favoráveis aos híbridos, contribuindo para que pudessem expressar mais intensamente seu potencial produtivo.

A pureza do caldo indica a porcentagem de sacarose em relação ao ${ }^{\circ}$ Brix. Os genótipos BRS506, BRS511 e CV198 apresentaram médias acima de $60 \%$ para a pureza do caldo, nos dois anos de cultivo (Tabela 1). Destaca-se ainda o desempenho de Past 29-49 no primeiro ano e CV007, CV147 e CV568 no segundo ano. May et al. (2012) encontraram valores de pureza do caldo de 54 a 73\%, com quatro variedades de sorgo sacarino, variação próxima a observada nesse estudo, de 42 até $76 \%$. Na cultura da cana-de-açúcar, os valores de pureza do caldo geralmente são superiores a $80 \%$ (Carvalho et al., 2008). Ressalta-se que os menores valores de pureza observados para o sorgo sacarino, com média de $56 \%$ e $58 \%$ nos anos de 2012/13 e 2013/14, respectivamente, podem ser explicados pela menor concentração de sacarose no caldo do sorgo, quando comparado com a cana-de-açúcar.

Não houve interação significativa entre anos de cultivo e genótipos para fibra (Tabela 1). Entre os genótipos, BRS506, BRS511, CV007 e CV147 apresentaram menores valores de fibra, diferindo significativamente dos demais. De acordo com Dias et al. (2012), quanto maior o teor de sacarose, menor é o percentual de fibra na cultura da cana-de-açúcar. Esta relação inversa também pode ser observada no sorgo sacarino nos genótipos BRS506 e BRS511 nos dois anos de cultivo e, CV007 e CV147 em 2013/14, os quais apresentaram elevados índices de sacarose e baixo teor de fibra.

A evolução do SST $/{ }^{\circ}$ Brix dos genótipos de sorgo sacarino define o período de utilização industrial (PUI) de cada genótipo, parâmetro importante para a colheita e programação de moagem nas usinas. Quanto ao limite do PUI para o sorgo sacarino, May et al. (2012) considera um valor de ${ }^{\circ}$ Brix de 14,25 a $14,5 \%$ no caldo. Neste trabalho, considerou-se o maior valor citado - ${ }^{\circ}$ Brix de $14,5 \%$ - para obtenção do PUI, exigindo-se, portanto, matéria-prima de melhor qualidade para a colheita. 
No primeiro ano de cultivo (Figura 3A e 3C), observou-se variação de 7 a $11 \%$ no ${ }^{\circ} B$ rix entre genótipos e no segundo ano de 10 a 14\% (Figura 3B e 3D), aos 2 dias após o florescimento (DAF). Davila-Gomez et al. (2011) encontraram ${ }^{\circ}$ Brix que oscilou entre 6 e $8 \%$ aos $7 \mathrm{DAF}$, sendo que os maiores valores foram obtidos a partir da terceira semana. No primeiro ano, as variedades BRS506 e Past 81-04 atingiram ${ }^{\circ} \mathrm{Brix}$ ideal aos 34 DAF e BRS511 aos 43 DAF, mantendo índices acima do limite até o final da avaliação. A variedade Past 29-51 (Figura 3A), no primeiro ano alcançou ${ }^{\circ}$ Brix limite apenas aos $90 \mathrm{DAF}$, e no ano seguinte aos 43 DAF (Figura $3 B$ ), sendo que nas demais avaliações permaneceu abaixo do limite estabelecido.

A variedade Fepagro 17 no primeiro ano (Figura 3A), apresentou ${ }^{\circ}$ Brix ideal para colheita apenas aos $76 \mathrm{DAF}$, enquanto no segundo ano manteve ${ }^{\circ} \mathrm{Brix}$ superior ao indicado dos 17 aos 34 DAF (Figura 3B), decrescendo posteriormente. A variedade Fepagro 19 apresentou acréscimos mais acentuados do ${ }^{\circ}$ Brix a partir de $55 \mathrm{DAF}$, permanecendo com valor superior ao limite dos 64 a 76 DAF (Figura 3A), decaindo na última avaliação. No segundo ano apresentou maior oscilação ao longo do período, mantendo-se com ${ }^{\circ}$ Brix próximo de 14,5\% dos 10 aos 25 DAF (Figura 3B). Past 29-49 apresentou no primeiro ano ${ }^{\circ}$ Brix superior ao ideal dos 64 aos $90 \mathrm{DAF}$, sendo que no segundo ano seu comportamento foi oposto, apresentando ${ }^{\circ}$ Brix mais elevado nas primeiras semanas após

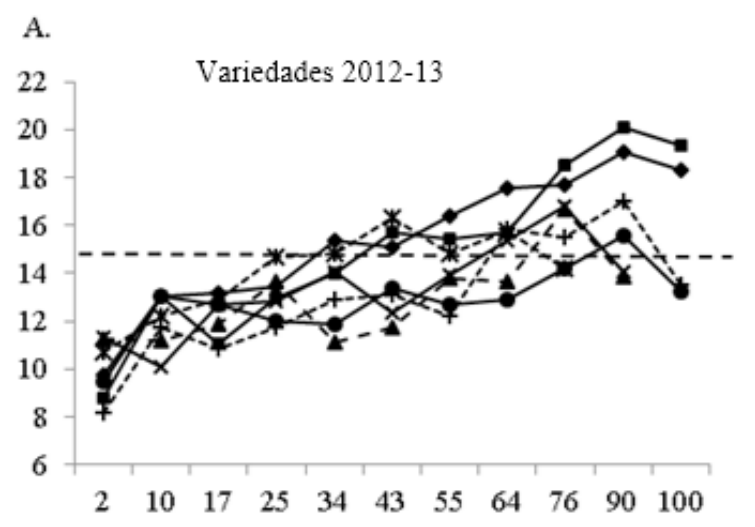

${ }^{\circ} \mathrm{Brix}$

$(\%)$

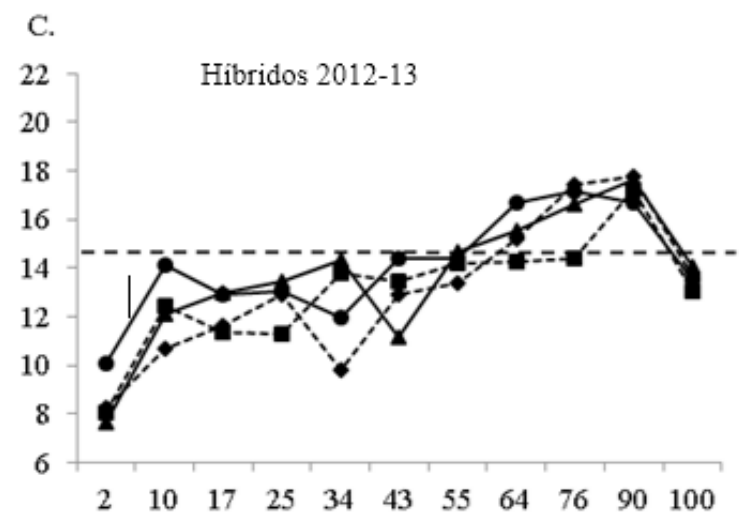

o florescimento.

Para os materiais híbridos, no primeiro ano de cultivo ocorreram elevações mais expressivas no ${ }^{\circ}$ Brix a partir de 55 DAF, sendo que o CV147 somente ultrapassou o valor limite aos 90 DAF (Figura $3 C$ ). Porém, no segundo ano os híbridos apresentaram comportamento diferente, pois CV568 e CV198 apresentaram ${ }^{\circ}$ Brix superior a $16 \%$ aos 10 DAF (Figura 3D) e mantiveram valores elevados na avaliação seguinte, decrescendo posteriormente. Os híbridos CV147 e CV007 apresentaram ${ }^{\circ}$ Brix adequado logo no início das avaliações, mantendo-se acima do valor limite durante todo o período avaliativo subsequente.

Os materiais de sorgo sacarino devem possuir um período de utilização industrial (PUI) mínimo de 30 dias, de acordo May et al. (2012). Adotando-se os critérios de limite e período de utilização industrial mínimo, somente os genótipos BRS506, BRS511 e CV198 (Figura 3) permaneceram acima dos valores limites nos dois anos de cultivo. Os genótipos Past 81-04, CV147 e CV007 somente atingiram o patamar estabelecido em um dos anos de cultivo.

No cultivo 2012/13 foi efetuado maior número de avaliações, observando-se também atraso no início da elevação do ${ }^{\circ}$ Brix, tanto nas variedades (Figura $3 \mathrm{~A}$ ) quanto nos híbridos (Figura 3C). Nesse primeiro ano de cultivo foi observado dano por acamamento em decorrência de ventos fortes com rajadas
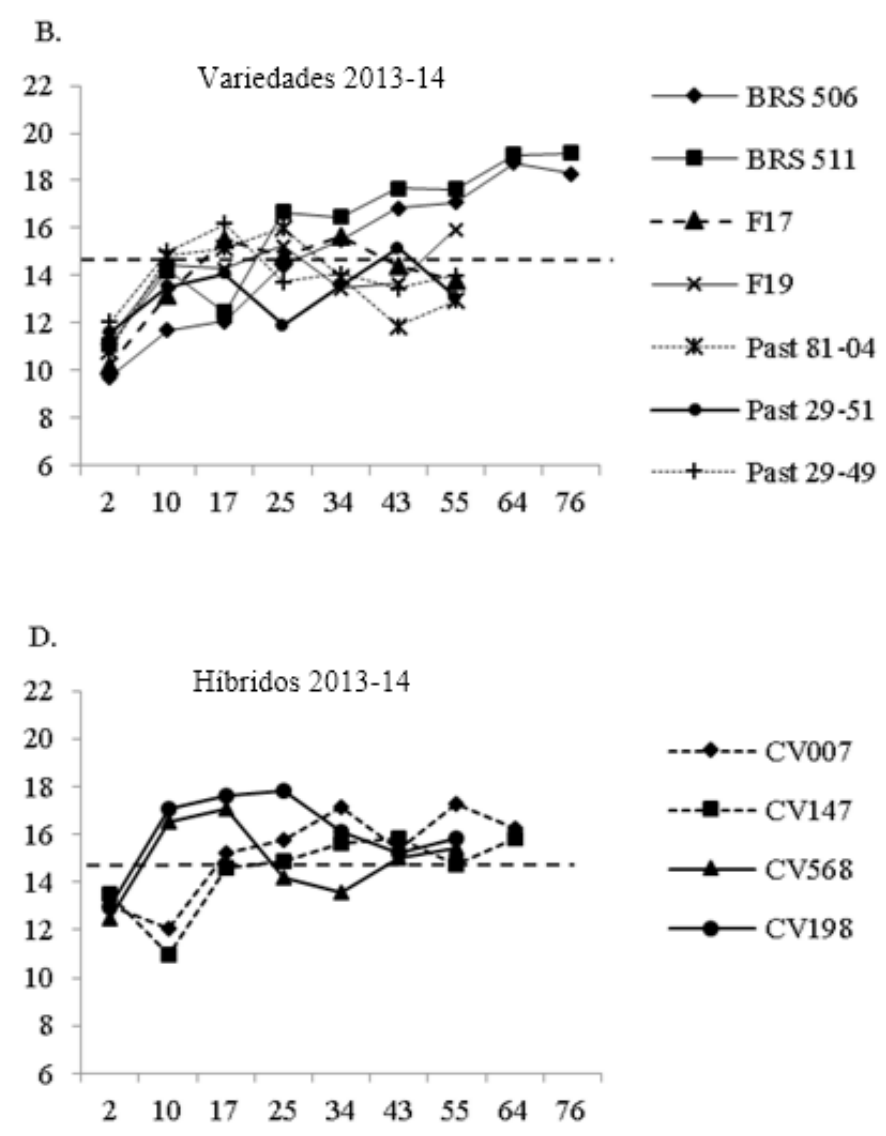

Dias após o florescimento (DAF)

Figura 3. Evolução do acúmulo de açúcares no colmo ( ${ }^{\circ}$ Brix) no período após o florescimento de sorgo sacarino em Santa Maria, RS. F17, Fepagro 17; F19, Fepagro 19. A linha tracejada indica o ${ }^{\circ}$ Brix mínimo (14,5\%) para determinação do período de utilização industrial. 
de até $67 \mathrm{~km} \mathrm{~h}^{-1}$ no dia 24/01/2013, época na qual a cultura ainda não havia iniciado o florescimento. Posteriormente, em decorrência do acamamento, foi observada emissão de raízes adventícias e perfilhos nos genótipos mais afetados, constituindo importantes drenos de carboidratos. Desta forma, a planta de sorgo redirecionou fotoassimilados para a emissão destes novos órgãos em detrimento do acúmulo de açúcares no colmo. Fato que ocasionou atraso do processo de maturação do colmo, constatado pelos valores de ${ }^{\circ}$ Brix abaixo do limite até os 55 DAF para a maioria dos genótipos. Notase que genótipos menos afetados pelo acamamento (Figura 2), como BRS506, BRS511 e Past 81-04, ultrapassaram o valor limite do ${ }^{\circ}$ Brix em menor tempo que os demais (Figura $3 \mathrm{~A}$ ), sendo que outros atingiram tal patamar em apenas uma ou duas das avaliações. Outra interferência relacionada ao acamamento pode ser associada ao descrito por Hills et al. (1990), os quais atribuíram o menor acúmulo de açúcar em genótipos de sorgo sacarino em consequência da menor área foliar exposta à radiação solar, devido ao excessivo sombreamento ocasionado pela sobreposição das plantas quando acamadas.

No segundo ano de cultivo, o maior dano por acamamento ocorreu em 15/03/2014, com rajadas de vento atingindo 58 $\mathrm{km} \mathrm{h}^{-1}$. Nessa data, a maioria dos genótipos encontrava-se no enchimento de grãos, ou seja, em processo intenso de acúmulo de açúcares no colmo, confirmado pelos valores de 'Brix acima do limite aos 17 DAF para a maioria dos genótipos (Figura 3B e 3D). Acrescenta-se ainda a ocorrência de maiores valores de temperatura do ar no período de janeiro a março de 2014 (Figura 1), fato que favoreceu o crescimento da cultura, pois a temperatura esteve mais próxima da ideal para o crescimento do sorgo, que se situa em torno de 33 a $34^{\circ} \mathrm{C}$ de acordo com Magalhães et al. (2000).

Destaca-se a precocidade dos híbridos CV568 e CV198 no segundo ano de cultivo, sendo que aos 10 DAF apresentaram ${ }^{\circ}$ Brix superior a $16 \%$ (Figura 3D), com pequeno incremento na avaliação subsequente (17 DAF). Dentre as variedades destacaram-se Past 24-49, Past 81-04 e F17, com valores ${ }^{\circ}$ Brix superiores ao limite na segunda avaliação, aos 17 DAF (Figura 3B). Desta forma, em anos com condições meteorológicas mais favoráveis, estes materiais genéticos, mesmo não apresentando PUI maior que 30 dias (exceto CV198), podem ser boas alternativas no planejamento da semeadura para colheita escalonada, oferecendo matéria-prima de qualidade poucos dias após o florescimento, enquanto BRS506 e BRS511 podem fornecer material mais tardiamente, quando apresentam os maiores valores de sólidos solúveis totais.

\section{Conclusões}

O ambiente de cultivo influencia significativamente os atributos qualitativos do sorgo sacarino, especialmente o rendimento de etanol nos híbridos.

Os genótipos BRS506, BRS511 e CV198 apresentam período de utilização industrial superior a 30 dias.
Os genótipos BRS506 e BRS511 apresentam maior potencial para produção de etanol.

\section{Literatura Citada}

Abd El-Razek, A.M.; Besheit, S.Y. Potential of some sweet sorghum (Sorghum bicolor L. Moench) varieties for syrup and ethanol production in Egypt. Sugar Tech, v.11, n.3, p.239-245, 2009. https://doi.org/10.1007/s12355-009-0041-5.

Almodares, A.; Hadi, M.R. Production of bioethanol from sweet sorghum: A review. African Journal of Agricultural Research, v.4, n.9, p.772-780, 2009. http://www.academicjournals.org/app/ webroot/article/article1380976619_Almodares\%20and\%20 Hadi.pdf. 30 Mai. 2016.

Alvim, K.R.T.; Brito, C.H.; Brandão, A.M.; Gomes, L.S.; Lopes, M.T.G. Quantificação da área foliar e efeito da desfolha em componentes de produção de milho. Ciência Rural, v.40, n.5, p.1017-1022, 2010. https://doi.org/10.1590/S0103-84782010000500003.

Câmara, T.M.M.; Parrella, R.A. da C.; Silva, H. De E. da. Qualidade industrial e rendimento de etanol de genótipos de sorgo sacarino em planta e rebrota. Revista Brasileira de Milho e Sorgo, v. 17, n. 2, p. 216-228, 2018. https://doi.org/10.18512/1980-6477/rbms. v17n2p216-228.

Carvalho, C.M. de; Azevedo, H.M. de; Dantas Neto, J.; Melo, E.P. de; Silva, C.T.S. da; Gomes Filho, R.R. Resposta dos atributos tecnológicos da terceira folha de cana-de-açúcar submetida a diferentes níveis de irrigação. Revista Brasileira de Ciências Agrárias, v.3, n.4, p.337-342, 2008. https://doi.org/10.5039/ agraria.v3i4a113.

Chavan, U.D.; Patil, J.V.; Shinde, M.S. An assessment of sweet sorghum cultivars for ethanol production. Sugar Tech, v.11, n.4, p.319-323, 2009. https://doi.org/10.1007/s12355-009-0056-y.

Comissão de Química e Fertilidade do Solo RS/SC - CQFS RS/SC. Manual de adubação e calagem para estados do Rio Grande do Sul e Santa Catarina. 10.ed. Porto Alegre: SBCS/NRS. 2004. 400p.

Companhia Nacional de Abastecimento - Conab. Acompanhamento da safra brasileira de cana-de-açúcar, safra 2014/15, quarto levantamento. Acompanhamento da safra brasileira de canade-açúcar, v.1 - Safra 2014/15, n.4, p.1-29, 2015. https://www. conab.gov.br/info-agro/safras/cana/boletim-da-safra-de-canade-acucar/item/download/1199_6d17e4217fb4a7eb35f603c18 b0b3e06. 31 Mai. 2016.

Conselho dos Produtores de Cana-de-Açúcar, Açúcar e Álcool do Estado de São Paulo - Consecana. Manual de instruções. Piracicaba: Consecana, 2006. 112p.

Davila-Gomez, F.J.; Chuck-Hernandez, C.; Perez-Carrillo, E.; Rooney, W.L.; Serna-Saldivar, S.O. Evaluation of bioethanol production from five different varieties of sweet and forage sorghums (Sorghum bicolor (L) Moench). Industrial Crops and Products, v.33, n.3, p. 611-616, 2011. https://doi.org/10.1016/j. indcrop.2010.12.022.

Dias, C.M.O.; Corsato, C.E.; Santos, V.M.; Santos, A.F.S. Indicadores fitotécnicos, de produção e agroindustriais em cana de açúcar cultivada sob dois regimes hídricos. Revista Caatinga, v.25, n.3, p.58-65, 2012. http://periodicos.ufersa.edu.br/revistas/index. php/sistema/article/view/2250/pdf_10. 31 Mai. 2016. 
Durães, F.O.M.; May, A.; Parrela, R.A. da C. Sistema agroindustrial do sorgo sacarino no Brasil e a participação público-privada: oportunidades, perspectivas e desafios. Sete Lagoas: Embrapa Milho e Sorgo, 2012. 76p. (Embrapa Milho e Sorgo. Documentos, 138). http://www.infoteca.cnptia.embrapa.br/handle/ doc/933001. 24 Mai. 2016.

Empresa Brasileira de Pesquisa Agropecuária - Embrapa. Sistema brasileiro de classificação de solos. Brasília: Embrapa Produções de Informações, 1999. 412p.

Emygdio, B.M. Desempenho da cultivar de sorgo sacarino BR 506 visando à produção de etanol em ambientes contrastantes. Pesquisa Agropecuária Gaúcha, v.17, n.1, p.45-51, 2011. http:// ainfo.cnptia.embrapa.br/digital/bitstream/item/63530/1/ Emygdio-20120629172607vol-17-n-1-art-06.pdf. 01 Jun. 2016.

Ferreira, D.F. SISVAR: um programa para análises e ensino de estatística. Revista Científica Symposium, v.6, n.2, p.36-41, 2008. http://www.dex.ufla.br/ danielff/meusarquivospdf/art63.pdf. 13 Mai. 2016.

Guigou, M.; Lareo, C.; Pérez, L.V.; Lluberas, M.E.; Vázquez, D.; Ferrari, M.D. Bioethanol production from sweet sorghum: Evaluation of post-harvest treatments on sugar extraction and fermentation. Biomass and Bioenergy, v.35, n.7, p.3058-3062, 2011. https:// doi.org/10.1016/j.biombioe.2011.04.028.

Hills, F.J.; Lewellen, R.T.; Skoyen, I.O. Sweet sorghum cultivars for alcohol production. California Agriculture, v.44, n.1, p.14-16, 1990. http://calag.ucanr.edu/archive/?type=pdf\&article=ca. v044n01p14. 13 Mai. 2016.

Instituto Nacional de Meteorologia - INMET. Banco de dados para ensino e pesquisa - BDMEP. http://www.inmet.gov.br/projetos/ rede/pesquisa. 20 Jan. 2015.

Intergovernmental Panel on Climate Change - IPCC. IPCC special report on renewable energy sources and climate change mitigation. Cambridge: Cambridge University Press; NewYork: IPCC, 2011. 26p.

Kawahigashi, H.; Kasuga, S.; Okuizumi, H.; Hiradate, S.; Yonemaru, J. Evaluation of Brix and sugar content in stem juice from sorghum varieties. Grassland Science, v.59, n.1, p.11-19, 2013. https://doi. org/10.1111/grs.12006.

Lessa, B.F. da. T.; Dutra, A.S.; Oliveira Filho, A.F. de; Silva, T.M. da; Silva, M.N.C.; Bezerra, M.A. Sweet sorghum for etanol production in the semi-arid: response to potassium silicate and maturation. Revista Brasileira de Ciências Agrárias, v.13, n.3, 2018. https:// doi.org/10.5039/agraria.v13i3a5548.

Magalhães, P.C.; Durães, F.O.M.; Schaffert, R.E. Fisiologia da planta de sorgo. Sete Lagoas: Embrapa Milho e Sorgo, 2000. 46 p. (Embrapa Milho e Sorgo. Circular técnica, 3). http://www.infoteca.cnptia. embrapa.br/handle/doc/484470. 20 Mai. 2016.
Martins, A. de M. Período de utilização industrial de cultivares de sorgo sacarino visando a produção de etanol na região central de Minas Gerais. Sete Lagoas: Universidade Federal de São João DelRei, 2013. 69f. Dissertação Mestrado. https://ufsj.edu.br/portal2repositorio/File/ppgca/DISSERTACAO\%20ALEXANDRE\%20 DE\%20MATOS\%20MARTINS\%202014(2).PDF. 21 Mai. 2016.

May, A.; Durães, F. Sorgo sacarino é a nova aposta para produção de álcool. Campo \& Negócios, v.9, n.109, p.64-65, 2012. https:// www.infoteca.cnptia.embrapa.br/infoteca/handle/doc/922493. 10 Jun. 2016.

May, A.; Durães, F.; Pereira Filho, I.A.; Schaffert, R.E.; Parrela, R.A. da C. Sistema Embrapa de produção agroindustrial de sorgo sacarino para bioetanol: sistema BRS1G - tecnologia qualidade Embrapa. Sete Lagoas: Embrapa Milho e Sorgo, 2012. 120p. (Embrapa Milho e Sorgo. Documentos, 139). http://www.infoteca.cnptia. embrapa.br/handle/doc/938275. 23 Mai. 2016.

Moreno, J.A. Clima do Rio Grande do Sul. Porto Alegre: Secretaria de Agricultura, Diretoria de Terras e Colonização, Secção de Geografia, 1961. 43p.

Pacheco, T.F. Índices tecnológicos industriais para produção de etanol de sorgo sacarino. In: Seminário Temático Agroindustrial de Produção de Sorgo Sacarino para Bioetanol, 1., 2012, Ribeirão Preto. Anais. Sete Lagoas: Embrapa Milho e Sorgo, 2012. p.24-28.

Parrela, R.A. da C. Melhoramento genético do sorgo sacarino. Agroenergia em Revista, v.2, n.3, p.8-9, 2011. http://www. infoteca.cnptia.embrapa.br/infoteca/handle/doc/901845. 12 Jun. 2016.

Pereira Filho, I.A.; Parrela, R.A. da C.; Moreira, J.A.A.; May, A.; Souza, V.F. de; Cruz, J.C. Avaliação de cultivares de sorgo sacarino [Sorghum bicolor (L.) Moench] em diferentes densidades de semeadura visando a características importantes na produção de etanol. Revista Brasileira de Milho e Sorgo, v.12, n.2, p.118-127, 2013. https://doi.org/10.18512/1980-6477/rbms. v12n2p118-127.

Smith, G.A.; Buxton, D.R. Temperate zone sweet sorghum ethanol production potential. Bioresource Technology, v.43, n.1, p.71-75, 1993. https://doi.org/10.1016/0960-8524(93)90086-Q.

Taiz, L.; Zeiger, E. Fisiologia vegetal. 5.ed. Porto Alegre: Artmed, 2013. $954 \mathrm{p}$.

Vanderlip, R.L.; Reeves, H.E. Growth stages of sorghum. Agronomy Journal, v.64, n.1, p.13-17, 1972. https://doi.org/10.2134/agronj 1972.00021962006400010005x.

Zhao, Y.L.; Dolat, A.; Steinberger, Y.; Wang, X.; Osman, A.; Xie, G.H. Biomass yield and changes in chemical composition of sweet sorghum cultivars grown for biofuel. Field Crops Research, v.111, p.55-64, 2009. https://doi.org/10.1016/j.fcr.2008.10.006. 